\title{
An improved cirrus detection algorithm MeCiDA2 for SEVIRI and its evaluation with MODIS
}

\author{
F. Ewald ${ }^{1,2}$, L. Bugliaro ${ }^{1}$, H. Mannstein ${ }^{1, *}$, and B. Mayer ${ }^{1,2}$ \\ ${ }^{1}$ Deutsches Zentrum für Luft- und Raumfahrt, Institut für Physik der Atmosphäre, Oberpfaffenhofen, Germany \\ ${ }^{2}$ Ludwig Maximilians Universität, Institut für Meteorologie, Munich, Germany \\ * deceased
}

Correspondence to: F. Ewald (florian.ewald@campus.lmu.de)

Received: 21 May 2012 - Published in Atmos. Meas. Tech. Discuss.: 1 August 2012

Revised: 31 December 2012 - Accepted: 3 January 2013 - Published: 11 February 2013

\begin{abstract}
In this study, a substantially improved version of the Meteosat cirrus detection algorithm (MeCiDA2) will be presented, which now allows application to the full earth disc visible by the Meteosat satellite. As cirrus clouds have an influence on the radiation budget of the earth, their optical properties and their global coverage has to be monitored at the global scale using instruments aboard geostationary satellites. Since MeCiDA was optimised for the area of Europe only, various changes were necessary to handle the variable conditions found over the full Meteosat disc. Required changes include the consideration of the viewing angle dependency and of the sensitivity of the $9.7 \mu \mathrm{m}$ channel to the ozone column. To this end, a correction is implemented that minimises the influence of the variability of the stratospheric ozone. The evaluation of the proposed improvements is carried out by using MeCiDA applied to MODIS (moderate resolution imaging spectrometer) data to address viewing angledependent cirrus detection, and by additionally comparing it to the cloud optical properties MOD06 cirrus product. The new MeCiDA version detects less cirrus than the original one for latitudes larger than $40^{\circ}$, but almost the same amount elsewhere. MeCiDA's version for MODIS is more sensitive than that for SEVIRI (spinning enhanced visible and infrared imager) with cirrus occurrences higher by $10 \%$, and the new MeCiDA provides almost the same cirrus coverage $( \pm 0.1)$ as given by the cloud phase optical properties from MODIS for latitudes smaller than $50^{\circ}$. Finally, the influence of sub-pixel clouds on the SEVIRI cirrus detection has been examined: more than $60 \%$ of the undetected SEVIRI cirrus pixels have a cirrus coverage smaller than 0.5 .
\end{abstract}

\section{Introduction}

Clouds, especially thin ice clouds, play an essential role in climate since they have have the ability to interact strongly with incoming and outgoing solar and terrestrial radiation. While thin ice clouds, so called cirrus clouds, reflect only a small portion of the incoming solar radiation, they are very effective at inhibiting the transmission of thermal radiation. Due to their location in the upper troposphere where low temperatures prevail, their emission of thermal radiation to space is small. Thus, the radiative forcing of cirrus clouds on the radiation balance at the top of atmosphere can be positive and may lead to a warming of the earth-atmosphere system. Furthermore, cirrus clouds can be of anthropogenic origin. The warm and humid exhaust of aircraft in this part of the atmosphere can lead to the formation of condensation trails (contrails) (Schmidt, 1941; Appleman, 1953; Schumann, 1996) that can eventually evolve into extended cirrus clouds (Duda et al., 2004; Atlas et al., 2006; Minnis et al., 1998, 2004; Jensen et al., 1998; Unterstrasser and Gierens, 2010). Changes in cirrus cloud cover or optical and physical properties can thus contribute to climate change.

For this reason, cirrus cloud remote sensing from space is an important and effective tool to monitor climate change. On polar orbiting satellites there are instruments that are very sensitive to cirrus clouds like the TIROS operational vertical sounder TOVS (Stubenrauch et al., 2006), the high resolution infrared radiation sounder HIRS (Wylie et al., 2005), the Stratospheric aerosol and gas experiment limb sounder SAGE II (Wylie and Wang, 1997), the atmospheric infrared sounder AIRS (Stubenrauch et al., 2010a), or the cloud-aerosol lidar with orthogonal polarization CALIOP 
Table 1. Met-8/SEVIRI channel numbers and corresponding Terra/MODIS band numbers with effective channel central wavelengths $\lambda_{\mathrm{c}}$.

\begin{tabular}{|c|c|c|c|c|c|c|c|c|c|c|c|c|}
\hline \multicolumn{13}{|c|}{ SEVIRI } \\
\hline Channel & 1 & 2 & 3 & 4 & 5 & 6 & 7 & 8 & 9 & 10 & 11 & 12 \\
\hline$\lambda_{\mathrm{c}} / \mu \mathrm{m}$ & 0.64 & 0.81 & 1.64 & 3.92 & 6.25 & 7.35 & 8.70 & 9.66 & 10.8 & 12.0 & 13.4 & 0.75 \\
\hline \multicolumn{13}{|c|}{ MODIS } \\
\hline Channel & 1 & 2 & 6 & $21-22$ & 27 & 28 & 29 & 30 & 31 & 32 & 33 & \\
\hline$\lambda_{\mathrm{c}} / \mu \mathrm{m}$ & 0.646 & 0.857 & 1.629 & 3.960 & 6.752 & 7.334 & 8.518 & 9.737 & 11.017 & 12.032 & 13.359 & \\
\hline
\end{tabular}

(Vaughan et al., 2004). Retrievals of cloud properties described by Schlüssel et al. (2005) also exist for the novel infrared atmospheric sounding interferometer (IASI), which have been reviewed by Lavanant et al. (2011) and Stubenrauch et al. (2010b). However, sounders have the disadvantage of a coarse spatial resolution, while lidars have a very limited spatial coverage due to their small footprint size. Moreover, polar orbiting platforms do not allow for the investigation of diurnal cycles of cirrus cloud coverage and properties. In contrast, passive optical instruments aboard geostationary satellites offer the possibility to investigate the diurnal cycles of clouds because of their high repeat cycle (usually between 5 and $30 \mathrm{~min}$ ) and their almost global spatial coverage. Because of this, the MeCiDA algorithm (Meteosat cirrus detection algorithm) was developed in Krebs et al. (2007) for application to MSG/SEVIRI (Meteosat second generation/spinning enhanced visible and infrared imager) (Sect. 2.1). This dedicated cirrus detection scheme uses exclusively the seven thermal channels of MSG/SEVIRI and employs morphological and multispectral threshold techniques to infer the presence of cirrus cloud inside MSG/SEVIRI pixels (Sect. 3.1). However, this algorithm has been developed and tuned for central Europe so that its global applicability is not guaranteed. In particular, the scheme does not contain any explicit viewing angle dependency and it has shown to be too sensitive to ozone properties due to the use of the MSG/SEVIRI channel centred at $9.7 \mu \mathrm{m}$ (see Sect. 4.1). During studies of the difference in cirrus coverage between the Northern and Southern Hemisphere far too high values for the cirrus coverage over the South Atlantic have been observed. Since this artefact leads to unrealistic overcast situations over large areas, its cause needs to be investigated in-depth.

To overcome these deficiencies, we have derived the function of the viewing angle dependency starting from an exhaustive radiative transfer simulation dataset (Sect. 4.2), and we have estimated the impact of stratospheric ozone amount on brightness temperatures measured at a wavelength of $9.7 \mu \mathrm{m}$ (Sect. 4.3). To test the impact of these changes we have made extensive use of MODIS (moderate resolution imaging spectrometer) data and products. First, we have adapted and applied MeCiDA to the MODIS instrument aboard the polar orbiting Terra satellite (Sect. 5.1). This enables us to compare the outcome of the same algorithm when applied to different sensors with different viewing angle geometries. On the other hand, we have compared cirrus cover maps derived from MeCiDA before and after the modifications to an independent cirrus cloud product on MODIS (the cloud phase optical properties) (Sect. 3.2). The results are illustrated in Sect. 6.

\section{Instruments}

The SEVIRI radiometer aboard the geostationary Meteosat second generation (MSG) satellite and the MODIS instrument aboard the polar orbiting Terra and Aqua spacecraft provide complementary information about clouds and their optical and microphysical properties. In particular, MODIS has 36 spectral channels with high spatial resolution $(\leq 1000 \mathrm{~m})$ and provides global coverage of the earth every one or two days with a repeat cycle of 16 days. In contrast, SEVIRI has a high temporal resolution $(\leq 15 \mathrm{~min})$ but a coarser spatial resolution and fewer spectral channels. Detailed characteristics of the two sensors are given in the next two subsections.

\subsection{SEVIRI}

The spinning enhanced visible and infrared imager SEVIRI (Schmetz et al., 2002) aboard the geostationary MSG satellite scans a large portion of the earth with 11 low resolution spectral bands of $3 \mathrm{~km}$ sampling distance and one high resolution visible (HRV) channel of $1 \mathrm{~km}$ sampling distance (see Table 1). The SEVIRI high temporal resolution of $15 \mathrm{~min}$ (or $5 \mathrm{~min}$ in rapid scan mode) enables a quantitatively investigation of the life cycle of clouds. Its seven thermal channels are onboard calibrated (10 bits), while the solar channels are not (vicarious calibration methods are used instead). The Meteosat second generation programme started in $\mathrm{Au}-$ gust 2002 with the launch of the first satellite (MSG1, renamed to Meteosat-8), continued in December 2005 with the MSG2 satellite (renamed to Meteosat-9) and should last until 2018 with two more satellites. 


\subsection{MODIS}

The moderate resolution imaging spectrometer MODIS provides high radiometric sensitivity (12 bit) in 36 spectral bands ranging from 0.4 to $14.4 \mu \mathrm{m}$. Two solar bands (bands $1-2)$ are imaged at a nominal resolution of $250 \mathrm{~m}$ at nadir, five solar bands (bands 3-7) at $500 \mathrm{~m}$, and the remaining 29 bands (bands $8-36$ ) at $1 \mathrm{~km}$. The MODIS bands corresponding to SEVIRI's channels are shown in Table 1. A \pm 55 -degree scanning pattern at the orbit height of $705 \mathrm{~km}$ achieves a $2330 \mathrm{~km}$ wide swath and provides global coverage every one to two days. MODIS is one of the key instruments aboard the polar orbiting sun-synchronous Earth observing system (EOS) spacecraft Terra and Aqua. Terra (EOS AM1), launched December 1999, is the morning satellite with an equator descending node crossing time of 10:30 UTC, while Aqua (EOS PM-1), launched May 2002, is the afternoon satellite with an equator ascending node crossing time of 13:30 UTC. In the following study we used the MODIS calibrated L1B radiance data (MOD02) with a horizontal resolution of $1 \mathrm{~km}$.

\section{Detection of cirrus clouds}

Cirrus cloud detection by means of passive imagers is a delicate task. The main reason is that cirrus often shows very low optical thickness and is hardly visible in solar channels over bright surfaces. At the same time, since its high transmissivity (and low emissivity) produces brightness temperatures that are a mixture of those from the surface and from the clouds, cirrus is difficult to detect in thermal channels as well. In contrast, optically thick water clouds are opaque and the surface albedo/temperature is irrelevant. Thus, advanced techniques must be employed to detect cirrus clouds. In this section we give an overview of two algorithms. The first one is the day- and nighttime Meteosat cirrus detection algorithm MeCiDA that has been developed by Krebs et al. (2007) to extract information about cirrus cloud contamination from thermal SEVIRI channels over central Europe. The second algorithm has been developed for application to MODIS by the NASA/MODIS team. Unlike the MeCiDA algorithm, the MODIS product cloud phase optical properties CPO is limited to daytime use only.

\subsection{SEVIRI: MeCiDA}

The Meteosat cirrus detection algorithm MeCiDA (Krebs et al., 2007) was developed to analyse the influence of air traffic on the diurnal cycle of cirrus clouds over central Europe. Please notice that in Krebs et al. (2007) and this paper, a cirrus cloud is any cloud whose topmost layer is composed of ice crystals. This means that not only thin cirrus clouds belong to this category but also cumuli and deep convective clouds with iced tops. This is in contrast to the synoptic definition of cirrus being only a thin ice cloud. As several studies have shown cirrus clouds are often closely connected with or even overlapping deep convection. However, passive remote sensing methods in the infrared from above the cloud struggle to separate cirrus clouds from iced tops of deep convection, just like deep convection leads to an underestimation of cirrus cover in ground-based observations. Since microwave measurements have shown that it remains hard to screen out deep convection in cirrus cloud coverage with existing IR methods (Evans et al., 1998; Hong et al., 2005), we continued with the definition of Krebs et al. (2007). The algorithm consists of six independent tests whose results are merged into one single cirrus mask (see Table 2 for an overview). Each test is considered as a stand-alone cirrus detection algorithm and tries to identify both thin and thick cirrus, even in the presence of an underlying water cloud. MeCiDA decides whether a SEVIRI pixel is cirrus covered by means of several threshold and morphological tests based on thermal channels alone. Therefore it enables the continuous monitoring of cirrus coverage. There are two different test groups, the multi-spectral threshold tests and the morphological tests. Tests $1-3$ and 6 belong to the first test group: they adopt brightness temperature differences (BTD) between various channel pairs to detect thin cirrus layers. Additional constraints on brightness temperatures (BT) or brightness temperature difference ensure that also very cold clouds and thick cirrus clouds are detected. Despite their basic similarity, Tests $1-3$ and Test 6 differ in two details (see Table 2):

- To enable a most general application, Tests 1-3 use socalled corrected brightness temperature differences: to produce these corrected BTDs the brightness temperature difference of the underlying feature (ground or water cloud) is subtracted from the measured brightness temperature difference. This difference is estimated using the warmest pixel in the neighbourhood as described in Krebs et al. (2007). Test 6 is not equipped with such a mechanism;

- If the pixels pointed at by the BTD test represent clouds whose tops are located in the upper troposphere they must be visible in one of the two SEVIRI water vapour channels; this additional constraint is implemented by means of a particular threshold test applied to a water vapour BT in Tests 1-3. Test 6 uses to this end a somewhat simpler BT test on the $\mathrm{CO}_{2}$ channel located around $13.4 \mu \mathrm{m}$.

These differences play an important role when analysing the performance of these tests.

The second test group comprising Test 4 and Test 5 exploit almost exclusively the morphology of the cirrus clouds in the water vapour channels: cirrus clouds appear as highfrequency structures on top of the otherwise very slowly changing water vapour fields. To extract the cirrus structures 
Table 2. Summary of the six cirrus tests and explanation of the filters used for the MeCiDA from Krebs et al. (2007) (called here MeCiDA1) and changes introduced in the revised cirrus tests that form the current version of the algorithm (called here MeCiDA2). Each individual cirrus test is contributing to the resulting cirrus mask.

\begin{tabular}{|c|c|c|}
\hline & MeCiDA1 & Changes in MeCiDA2 \\
\hline \multirow[t]{3}{*}{ Test 1} & $\begin{array}{l}{\mathrm{T} 1 \mathrm{a}_{n \times n}}=\left[\left(T_{10.8}-T_{12.0}\right)-\left(T_{10.8, \max (n \times n)}-T_{12.0, \max (n \times n)}\right)>0.6 \mathrm{~K}\right] \\
\text { and }\left[T_{7.3, \operatorname{box}(19 \times 19)}-T_{7.3}>0.5 \mathrm{~K}\right]\end{array}$ & \\
\hline & $\mathrm{T} 1 \mathrm{~b}=\left[T_{6.2}-T_{7.3}>-12 \mathrm{~K}\right]$ & $\mathrm{T} 1 \mathrm{~b}=\left[T_{6.2}-T_{7.3}>\left(-7.7-10.0 \mu+4.5 \mu^{2}\right) \mathrm{K}\right]$ \\
\hline & $\mathrm{T} 1=\left[\mathrm{T}_{1} \mathrm{a}_{3 \times 3}\right.$ or $\mathrm{T}_{1} \mathrm{a}_{9 \times 9}$ or $\left.\mathrm{T}_{1} \mathrm{a}_{19 \times 19}\right]$ or $\mathrm{T} 1 \mathrm{~b}$ & \\
\hline \multirow[t]{4}{*}{ Test 2} & $\mathrm{~T} 2 \mathrm{a}=\left[\left(T_{8.7}-T_{12.0}\right)-\left(T_{8.7, \max (19 \times 19)}-T_{12.0, \max (19 \times 19)}\right)>1.6 \mathrm{~K}\right]$ & and $\left[\left(T_{6.2, \operatorname{box}(19 \times 19)}-T_{6.2}\right)>0.5 \mathrm{~K}\right]$ \\
\hline & $\mathrm{T} 2 \mathrm{~b}=\left(T_{6.2}-T_{7.3}\right)>-12 \mathrm{~K}$ & $\mathrm{~T} 2 \mathrm{~b}=\left[T_{6.2}-T_{7.3}>\left(-7.7-10.0 \mu+4.5 \mu^{2}\right) K\right]$ \\
\hline & $\mathrm{T} 2 \mathrm{c}=\left(T_{8.7}-T_{10.8}\right)>0 \mathrm{~K}$ & \\
\hline & $\mathrm{T} 2=[\mathrm{T} 2 \mathrm{a}$ or $\mathrm{T} 2 \mathrm{~b}$ or $\mathrm{T} 2 \mathrm{c}]$ & \\
\hline \multirow[t]{3}{*}{ Test 3} & $\begin{array}{l}\mathrm{T} 3 \mathrm{a}=\left[\left(T_{9.7}-T_{13.4}\right)-\left(T_{9.7, \max (19 \times 19)}-T_{13.4, \max (19 \times 19)}\right)>3.5 \mathrm{~K}\right] \\
\text { and }\left[\left(T_{7.3, \operatorname{box}(19 \times 19)}-T_{7.3}\right)>0.5 \mathrm{~K}\right]\end{array}$ & \\
\hline & $\mathrm{T} 3 \mathrm{~b}=\left(T_{6.2}-T_{7.3}\right)>-12 \mathrm{~K}$ & $\mathrm{~T} 3 \mathrm{~b}=\left[T_{6.2}-T_{7.3}>\left(-7.7-10.0 \mu+4.5 \mu^{2}\right) K\right]$ \\
\hline & $\mathrm{T} 3=[\mathrm{T} 3 \mathrm{a}$ or $\mathrm{T} 3 \mathrm{~b}]$ & \\
\hline \multirow[t]{5}{*}{ Test 4} & $\mathrm{~T} 4 \mathrm{a}=\left[\left(T_{7.3, \operatorname{box}(15 \times 15)}-T_{7.3}\right)>0.5 \mathrm{~K}\right]$ & and $\left[T_{7.3, \text { gauss }(15 \times 15)}>0.5 \mathrm{~K}\right]$ \\
\hline & $\mathrm{T} 4 \mathrm{a}=\left[\left(T_{7.3, \operatorname{box}(15 \times 15)}-T_{7.3}\right)>0.5 \mathrm{~K}\right]$ & and $\left[T_{7.3, \text { gauss }(15 \times 15)}>0.5 \mathrm{~K}\right]$ \\
\hline & and $\left[T_{13.4}<253 \mathrm{~K}\right]$ & and $\left[T_{13.4}<\left(219.3+49.6 \mu-21.7 \mu^{2}\right) K\right]$ \\
\hline & $\mathrm{T} 4 \mathrm{~b}=T_{13.4}<233 \mathrm{~K}$ & $\mathrm{~T} 4 \mathrm{~b}=T_{13.4}<\left[T_{13.4}<\left(199.3+49.6 \mu-21.7 \mu^{2}\right) K\right]$ \\
\hline & $\mathrm{T} 4=[\mathrm{T} 4 \mathrm{a}$ or $\mathrm{T} 4 \mathrm{~b}]$ & \\
\hline \multirow[t]{5}{*}{ Test 5} & $\mathrm{~T} 5 \mathrm{a}=\left[\left(T_{6.2}-T_{7.3}\right)_{\mathrm{box}(15 \times 15)}-\left(T_{6.2}-T_{7.3}\right)>1 \mathrm{~K}\right]$ & $\mathrm{T} 5 \mathrm{a}=\left[\left(T_{6.2}-T_{7.3}\right)_{\mathrm{box}(15 \times 15)}-\left(T_{6.2}-T_{7.3}\right)>1 \mathrm{~K}\right]$ \\
\hline & and $\left[\left(T_{6.2}-T_{7.3}\right)_{\text {gauss }(15 \times 15)}>1 \mathrm{~K}\right]$ & and $\left[\left(T_{6.2}-T_{7.3}\right)_{\text {gauss }(15 \times 15)}>1 \mathrm{~K}\right]$ \\
\hline & and $\left[T_{13.4}<253 \mathrm{~K}\right]$ & and $\left[T_{13.4}<\left(219.3+49.6 \mu-21.7 \mu^{2}\right) K\right]$ \\
\hline & $\mathrm{T} 5 \mathrm{~b}=\left[T_{13.4}<233 \mathrm{~K}\right]$ & $\mathrm{T} 5 \mathrm{~b}=\left[T_{13.4}<\left(199.3+49.6 \mu-21.7 \mu^{2}\right) K\right]$ \\
\hline & $\mathrm{T} 5=[\mathrm{T} 5 \mathrm{a}$ or $\mathrm{T} 5 \mathrm{~b}]$ & \\
\hline \multirow[t]{4}{*}{ Test 6} & $\mathrm{~T} 6 \mathrm{a}=\left[\left(T_{9.7}-T_{13.4}\right)>-7 \mathrm{~K}\right]$ & $\mathrm{T} 6 \mathrm{a}=\left[T_{9.7}-T_{10.8}>\left(-16.0+11.3 \mu-1.2 \mu^{2}\right)+\Delta T_{\mathrm{corr}}^{\mathrm{O}_{3}}\right.$ \\
\hline & and $\left[T_{13.4}<258 \mathrm{~K}\right]$ & and $T_{13.4}<\left(224.3+49.6 \mu-21.7 \mu^{2}\right) K$ \\
\hline & $\mathrm{T} 6 \mathrm{~b}=T_{13.4}<243 K$ & $\mathrm{~T} 6 \mathrm{~b}=T_{13.4}<\left(209.3+49.6 \mu-21.7 \mu^{2}\right) K$ \\
\hline & $\mathrm{T} 6=[\mathrm{T} 6 \mathrm{a}$ or $\mathrm{T} 6 \mathrm{~b}]$ & \\
\hline \multirow[t]{5}{*}{ Filters } & \multicolumn{2}{|c|}{$T_{12.0, \max (n \times n)}$ denotes the maximum brightness temperature in an area of $n \times n$ pixels centred around the pixel under consideration. } \\
\hline & \multicolumn{2}{|c|}{$T_{7.3 \text {, box }(n \times n)}$ denotes the average brightness temperature in an area of $n \times n$ pixels centred around the pixel under consideration. } \\
\hline & \multicolumn{2}{|l|}{$\left(T_{6.2}-T_{7.3}\right)_{\text {gauss }(15 \times 15)}$ is a Gaussian filter according to Eqs. (2) and (1). } \\
\hline & \multicolumn{2}{|l|}{$\mu=\cos \theta$ is the cosine of the satellite zenith angle. } \\
\hline & \multicolumn{2}{|l|}{$\Delta T_{\text {corr }}^{\mathrm{O}_{3}}$ is computed according to Sect. 4.3 . } \\
\hline
\end{tabular}

various high-pass filters are applied to extract information about the so-called "local standard deviation". The corresponding local deviation filter operation reads as

$g_{i, j}=\sqrt{\left(f_{i, j} \odot K-f_{i, j}\right)^{2} \odot K}$, where $\odot$ is the convolution operator, $f_{i, j}$ is the original image, $K$ is a Gaussian convolution kernel and $g_{i, j}$ is the filtered image. The difference between the original and the smoothed image is squared and the result is smoothed again. The convolution kernel $K(x, y)$ is 
a)

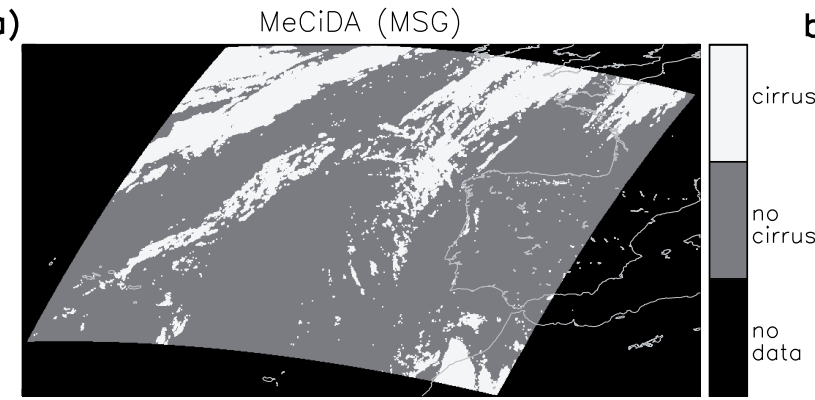

b)

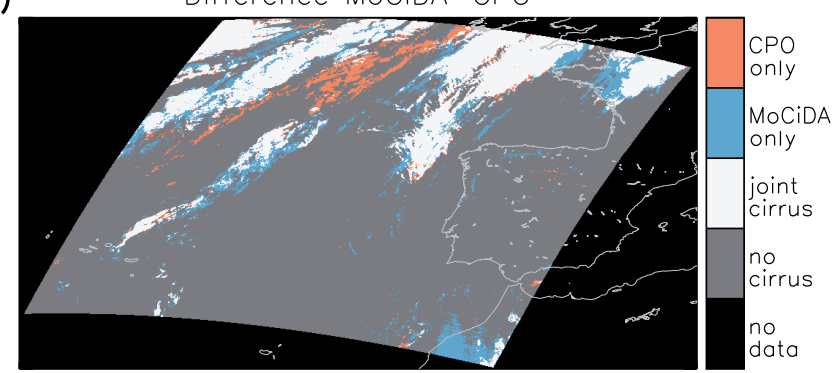

Fig. 1. Sample cirrus products for 11 January 2009, 12:00 UTC, west of Spain/Portugal. (a) Cirrus mask from MoCiDA2 applied to the MSG/SEVIRI slot closest in time. (b) Difference between the MoCiDA2 and the CPO cirrus masks (both extracted from MODIS data): red and blue identify cirrus pixels that are detected by CPO or MoCiDA2 alone, white means cirrus pixels that are detected by both algorithms, while grey corresponds to cirrus free pixels.

$K(x, y)=\frac{1}{N} \exp \left(-\frac{x^{2}+y^{2}}{2 \cdot\left(\frac{s}{4}\right)^{2}}\right)$,

where $N$ is a factor that normalizes the sum of all kernel values to unity, $s$ is the kernel size (an odd number) which we set to 15 for our application, and $x$ and $y$ are in the range from $-(s-1) / 2$ to $+(s-1) / 2$.

Figure 1 shows an example of MeCiDA cirrus mask (panel a) for a MODIS granule acquired on 11 January 2009 at 12:00 UTC. A false colour composite using MODIS band 1 , band 2 and the inverted band 31 (see Table 1) is depicted in Fig. 2, in MSG/SEVIRI projection. This channel combination has been selected for the RGB because it allows a visual discrimination of clouds: low clouds exhibit a yellow colour, thick high clouds are white and thin ice clouds are violet. This is useful for testing the plausibility of the cirrus masks produced by the algorithms. In this case, $\mathrm{MeCiDA}$ produces an accurate cirrus distribution. All the cirrus clouds in the northern part of the picture (Fig. 1) are also visible in the RGB (Fig. 2). However, in the lower right corner MeCiDA detects a cirrus cloud that cannot be identified in the RGB.

\subsection{MODIS: CPO}

The cloud phase optical properties (CPO) is a scientific dataset contained in the operational MODIS cloud retrieval (product name MOD06 for MODIS Terra) which is derived from MODIS radiance data. This dataset combines information from visible and thermal MODIS bands to infer cloud phase. It is the basis for the derivation of cloud optical thickness and cloud effective radius and is described in Platnick et al. (2003). Its structure is quite elaborate: it combines cloud mask results (Ackerman et al., 1998) with a bispectral thermal algorithm and a shortwave infrared algorithm. The bispectral algorithm (Baum et al., 2000) exploits the stronger absorption of radiation by ice with respect to water at $11 \mu \mathrm{m}$ when compared to $8.5 \mu \mathrm{m}$. The shortwave infrared algorithm consists of threshold tests applied to the ratio of

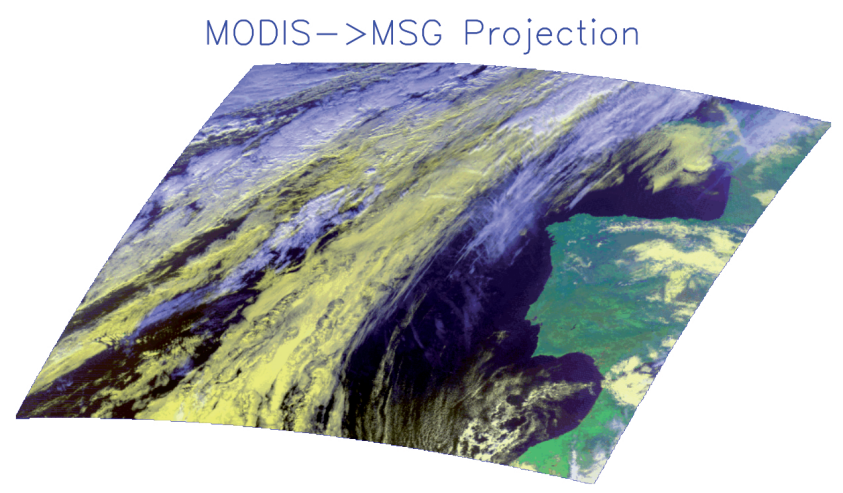

Fig. 2. MODIS false colour composite in MSG/SEVIRI projection. For 11 January 2009, 12:00 UTC, west of Spain/Portugal.

a near infrared channel $(1.61$ or $2.13 \mu \mathrm{m})$ to a shortwave infrared channel $(0.65,0.86$ or $1.24 \mu \mathrm{m}$, depending on surface type). At the near infrared wavelengths, absorption of radiation by water and ice particles takes place as a function of thermodynamic phase and particle radius while at the shorter wavelengths only scattering matters. The "bispectral thermal algorithm" provides an initial phase determination and serves as fallback for the "shortwave infrared algorithm", which is available with a spatial resolution of $1 \mathrm{~km} \times 1 \mathrm{~km}$. The cloud phase optical properties offers a sophisticated detection of cloud phase during daytime, though the phase discrimination for optically thin cirrus and supercooled water drops remains problematic (Platnick et al., 2003) as with other algorithms relying on passive instruments.

\section{Improved cirrus detection with SEVIRI}

\subsection{Deficiencies of MeCiDA1}

During an investigation of cirrus clouds in the Southern Atlantic a striking feature was observed: during the southern spring cirrus coverage started to increase and rapidly reached 
$100 \%$. This unrealistic behaviour could be identified to be a failure of Test 6 in this region due to its dependency on the ozone channel located at $9.7 \mu \mathrm{m}$ and the presence of the ozone hole and the following reduction of ozone at midlatitudes, which is a typical phenomenon for Southern Hemisphere spring. This illustrates the fact that MeCiDA had been developed for central Europe and was not directly applicable to other regions. Another related issue is the lack of a viewing angle dependency of the thresholds used in the tests. This was due again to the fact that the original algorithm had been tested and tuned for central Europe where the SEVIRI viewing angle ranges approximately between 50 and $65^{\circ}$.

\subsection{Viewing angle dependency}

The atmospheric path of radiation emitted by the earthatmosphere system increases with satellite viewing angle, i.e. when regions closer to the horizon are observed. Because of the presence of (weak or strong) gas absorption bands in all the thermal channels, the measured BTs decrease with satellite viewing angle because the path length for radiation is longer. Absorption of radiation from warm layers of the atmosphere is intensified along the line of sight as well as the emission of radiation from colder layers of the atmosphere (limb darkening). This effect mainly affects the BT tests of MeCiDA but has not been considered up to now. Tests 13 use corrected BTDs and are less affected since the subtraction of the BTD of the underlying or surrounding feature from the measured BTDs partly accounts for this effect. Test 6 also belongs to the BTD test group (see Sect. 3.1) but will be analysed in more detail in Sect. 4.3 due to its ozone dependency (see Sect. 4.1).

In order to correctly take into account the viewing angle dependency, the extensive radiative transfer simulation dataset has been used, which was also employed during the development of MeCiDA (see also Krebs et al., 2007, Sect. 2.2). It comprises detailed radiative transfer calculations based on random variation of all relevant input data to cover a wide range of possible conditions. The details of radiative transfer calculations performed with the libRadtran (library for radiative transfer) package (Mayer and Kylling, 2005) can be found in Krebs et al. (2007).

In order to determine viewing angle dependent thresholds, for the BT and BTDs used in the MeCiDA tests, we computed the two-dimensional histogram of the BTs of these channels or channel combinations as a function of the cosine of the satellite zenith angle $\mu=\cos \theta$. Figure 3 shows an example for the channel at $13.4 \mu \mathrm{m}$. The red "ridge" in this plot corresponds to situations without cirrus clouds, while the blue "ridge" corresponds to situations with cirrus clouds. Of course, the absence of cirrus is mirrored in high BTs but the decrease of these cloudless BTs with increasing satellite zenith angle is not negligible. The determination of new, angle-dependent thresholds was done for each $\mu$ separately, as described in the following: for each $\mu$ contained in the

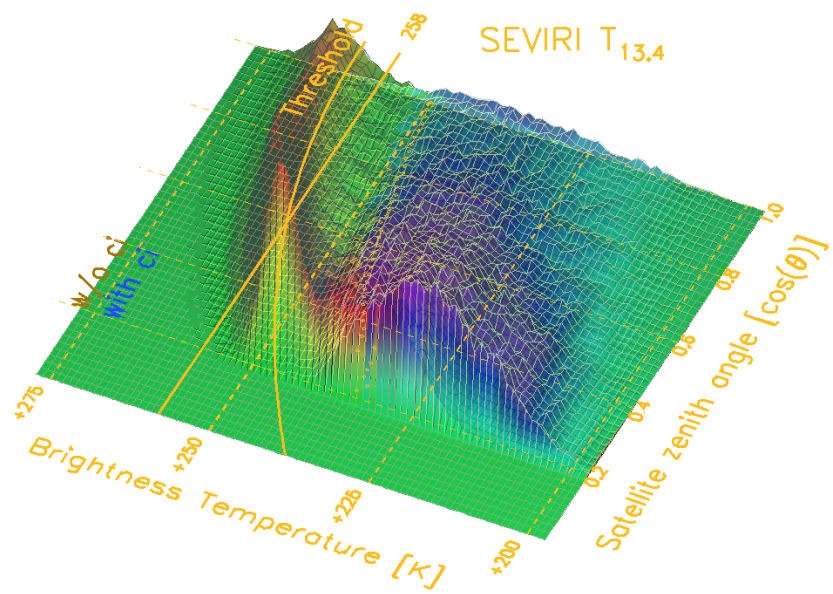

Fig. 3. 2D-histogram of simulated BT of the SEVIRI channel centred at $13.4 \mu \mathrm{m}$ as a function of the cosine of the satellite zenith angle $\mu=\cos \theta$. In addition, the fixed threshold used in MeCiDA Test 6 of $258 \mathrm{~K}$ is plotted together with the new $\mu$ dependent threshold function.

simulations, we approximated the red and blue "ridge" in Fig. 3 by means of two Gaussian fits. The mean values of these two Gaussian curves mark the "baseline" of both BT distributions. Their mean value lies always within the trough between the red and blue "ridge" and serves as a separation between both distributions. Finally, a quadratic function $T(\mu)=a \mu^{2}+b \mu+c$ was fitted to these separating mean values. This fitted function $T(\mu)$ represents the desired satellite viewing angle dependent threshold function.

Since MeCiDA was originally tuned for central Europe (Krebs et al., 2007) where it proved to be accurate, our intention was to keep its performance over this region unchanged. Thus, an offset value was calculated such that the value of the quadratic function $T(\mu)$ determined above at $\mu \approx 0.5$, corresponding to the approximate mean $\mu$ value for this region, was shifted to the original value given in Krebs et al. (2007).

For all other values of $\mu$ we applied a scaling factor to this shift since the curvature of $T(\mu)$ varies as a function of $\mu$. This scaling factor was calculated by taking the ratio of the spread between the red and blue "ridge" at $\mu$ and the spread at $\mu=0.5$. This procedure guarantees the continuity between the old and the new algorithm over Europe with simultaneous consideration of a proper differentiation between scenes with and without cirrus for other regions.

This way, all "simple" threshold tests in MeCiDA that do not use corrected BTDs, but simple BTDs or BTs, could be modified to take into account the satellite viewing angle dependency. The results are displayed in Table 2 together with the original values of the thresholds.

\subsection{Cirrus detection with the $9.7 \mu \mathrm{m}$ SEVIRI channel}

As already mentioned in Sect. 4.1, a misidentification is produced by the BTD Test $6 \mathrm{a}, T_{9.7}-T_{13.4}>-7 \mathrm{~K}$, because the 
constant threshold employed in this test is not capable to distinguish between cirrus and cirrus free pixels during the course of the year. In fact, the threshold should take into account the annual cycle of ozone since ozone concentrations (and vertical temperature profiles) affect the BT at $9.7 \mu \mathrm{m}$. This effect is exemplified by the consideration of this BTD over a region in the South Atlantic located between $45-55^{\circ} \mathrm{S}$, $45-10^{\circ} \mathrm{W}$, called SAR in the following, as shown in Fig. 4. To this end, MeCiDA Tests 1-5 were applied to all the available time slots in the year 2007. While MeCiDA Test 6 turned out to be unreliable in this region, the remaining tests proved to yield low false alarm rates such that they could be used to roughly determine which pixels are cirrus covered and which ones are not. Using MeCiDA Tests 1-5 to separate between cloudy and cloudless pixels, we derived $T_{9.7}-T_{13.4}$ for pixels with and without cirrus and computed the spatial averages for the SAR region. Both cirrus covered and cirrus free BTDs are plotted in Fig. 4. The two curves are separated by approximately $5 \mathrm{~K}$ and show a pronounced annual cycle of approximately $5 \mathrm{~K}$. This effect is sufficient to produce misdetections at the beginning and at the end of the year in this region (see threshold line in Fig. 4).

The observed annual cycle is produced by both the ozone and the $\mathrm{CO}_{2}$ channels, i.e. the $9.7 \mu \mathrm{m}$ and the $13.4 \mu \mathrm{m}$ channels. The channel at $9.7 \mu \mathrm{m}$ differs from all other thermal channels in that the main part of the absorber gas ozone affecting measurements in this spectral interval is located in the stratosphere, i.e. above the clouds, especially also above the cirrus clouds. Thus, while water vapour, for instance, becomes almost irrelevant in the $10.8 \mu \mathrm{m}$ channel when a high cloud is present in the atmosphere, the ozone concentration is still crucial for the interpretation of the ozone channel measurement.

During the distinct stratospheric warming over the SAR region, starting in southern spring at the onset of the ozone destruction by the exposure to sunlight, one can observe considerable spikes in $9.7 \mu \mathrm{m}$ temperatures. High ozone concentrations prevalent at that time lead to higher BTs in this channel in the presence of a cirrus cloud since the ozone layer is located in a part of the stratosphere with higher temperatures than the cirrus cloud top temperature. In contrast, with the presence of low clouds or in the cloud free case, an increased ozone concentration leads to lower temperatures in this channel since stratospheric ozone layer temperatures are lower than near ground temperatures. Using again the set of radiative transfer simulations described in Sect. 4.2, we show that a variability of the ozone column by $\pm 50 \mathrm{DU}$ causes variability in brightness temperature of $\pm 5 \mathrm{~K}$ in the SEVIRI $9.7 \mu \mathrm{m}$ channel. According to Kurzeja (1984), planetary waves at high latitudes are responsible for a variation of the ozone column of up to $\pm 60 \mathrm{DU}$. The mean annual cycle of ozone lies also in this range (Jiang et al., 2008a,b). The very low temperatures of the ozone layer in polar winter also have a cooling effect on the ozone channel. Finally, these effects are enhanced close to the SEVIRI horizon due

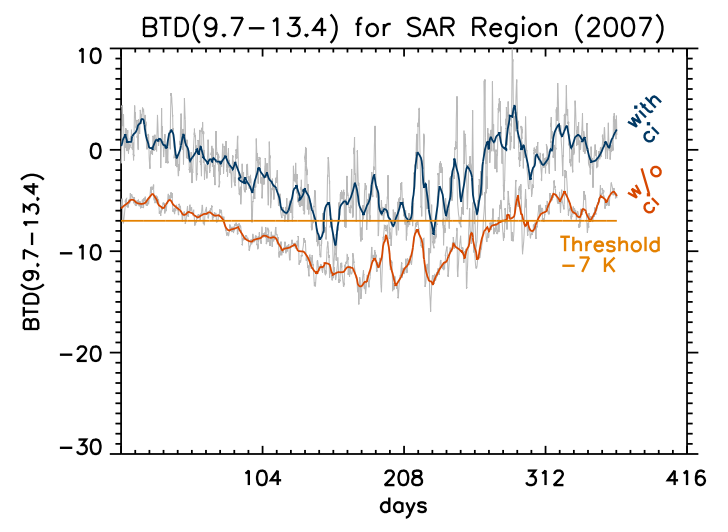

Fig. 4. Mean daily BTD $T_{9.7}-T_{13.4}$ for those SEVIRI pixels that have been detected as cirrus covered (blue) or cirrus free (red) by MeCiDA Tests 1-5 over SAR as a function of time during the year 2007. Grey curves represent the same BTD but with the full temporal resolution of $15 \mathrm{~min}$.

to the slant view of the satellite. The $13.4 \mu \mathrm{m}$ channel also presents an annual cycle, but to a lower extent than the ozone channel. The $\mathrm{CO}_{2}$ gas is well-mixed in the troposphere such that the $13.4 \mu \mathrm{m}$ channel temperatures are less sensitive to air temperature changes in confined atmospheric layers like the stratosphere. The $13.4 \mu \mathrm{m}$ BTs over optically-thick cirrus clouds fluctuate between $240 \mathrm{~K}$ in summer and $225 \mathrm{~K}$ in winter, which can be assigned solely to changes in atmosphere temperatures as there is no significant fluctuation in $\mathrm{CO}_{2}$ concentrations.

Since we wanted to keep the ozone channel at $9.7 \mu \mathrm{m}$ in our detection algorithm in order to maintain a broad variety of cirrus tests in MeCiDA, we decided to modify Test $6 \mathrm{a}$ in such a way as to produce a larger temperature difference between the cirrus covered and the cirrus free case that is independent of time of the year. Moreover, the contribution of test 6 to the overall cirrus cloud coverage is quite significant (compare Krebs et al., 2007, Fig. 12). Since the continuity in detection performance over europe was one of the main objectives of this study, Test 6 was also included in the new algorithm (MeCiDA2). To this end, the $\mathrm{CO}_{2}$ channel was replaced with the $10.8 \mu \mathrm{m}$ channel and the channel combination $T_{9.7}-T_{10.8}$ was selected. Although this BTD shows a pronounced annual cycle for both cirrus free and cirrus covered pixels (see Fig. 5a), for cirrus contaminated observations this is mainly produced by the ozone channel alone since cirrus measurements in the atmospheric window channel centred at $10.8 \mu \mathrm{m}$ have a moderate dependency on time of the year between $245 \mathrm{~K}$ in summer and $235 \mathrm{~K}$ in winter. The result of this substitution is plotted in Fig. 5a as a function of day of the year averaged over the SAR region in 2007 for both cirrus and cirrus free pixels (again obtained from MeCiDA Tests 1-5).

These two curves are apart by more than $10 \mathrm{~K}$, thus confirming a strong sensitivity of this new channel difference on 

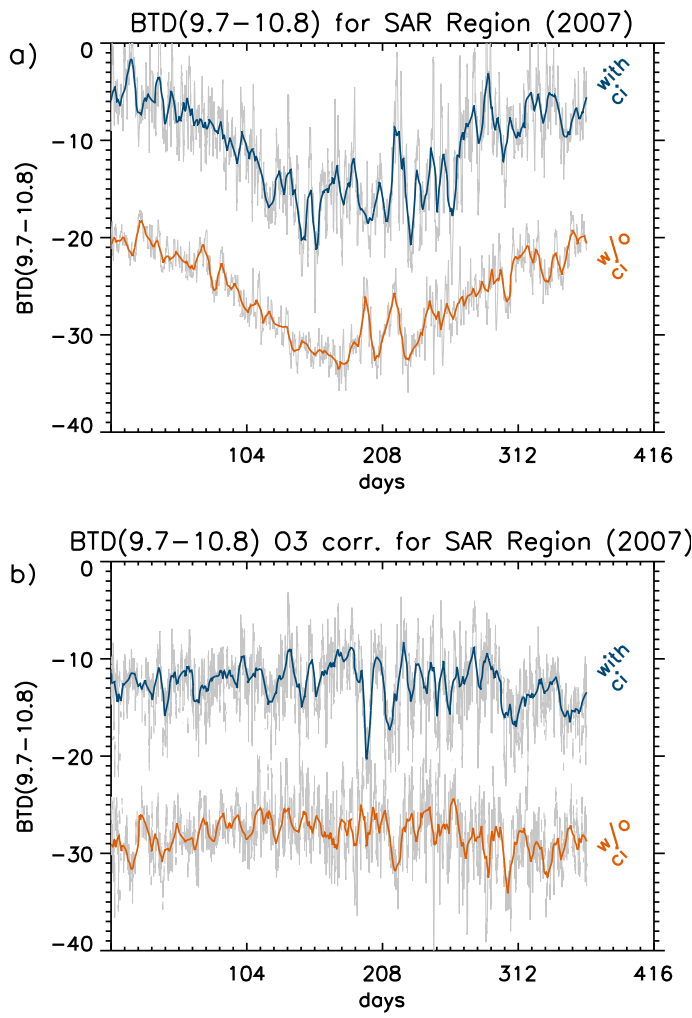

Fig. 5. (a) Daily mean of $T_{9.7}-T_{10.8}$ for MeCiDA Tests $1-5$ cirrus clouds (blue) and cirrus free pixels (red) averaged over the SAR region as a function of day of the year in 2007. (b) Daily mean of $T_{9.7}-T_{10.8}$ after correction of the ozone annual cycle for MeCiDA Tests $1-5$ cirrus clouds (blue) and cirrus free pixels (red) averaged over the SAR region as a function of day of the year in 2007. Grey curves represent the same BTDs but with the full temporal resolution of $15 \mathrm{~min}$.

cirrus clouds and making it easier to differentiate between cirrus covered and cirrus free pixels. Second, to mitigate the effect of varying ozone concentrations on this channel combination, a correction was added by considering very cold (thick) cirrus pixels with $10.8 \mu \mathrm{m}$ brightness temperatures $T_{10.8}$ smaller than $238 \mathrm{~K}$. This value for an average viewing angle over central Europe $(\mu=0.5)$ is adapted to other viewing angles in the same way like the other tests (Table 2 , Test $6 \mathrm{a})$. In the case of cold cirrus clouds, the $T_{9.7}-T_{10.8}$ is a proxy for the influence of stratospheric ozone on $9.7 \mu \mathrm{m}$ channel measurements and can be used to reduce the effect of the annual cycle of ozone on $T_{9.7}$ measurements, i.e. to produce a correction term $\Delta T_{\text {corr }}^{\mathrm{O}_{3}}$ to be added to the $T_{9.7}$ brightness temperature.

We proceed like this: first, all pixels with $T_{10.8}<$ $\left(230.1+17.3 \mu-6.4 \mu^{2}\right) \mathrm{K}$ are marked. This threshold was determined using the same method as in Sect. 4.2 and corresponds to $T_{10.8}<238 \mathrm{~K}$ over Europe. Then, connected cloud pixels are identified and their $T_{9.7}-T_{10.8}$ temperature differences are averaged into a single value. To obtain an upper estimate for the ozone influence on $T_{9.7}$ only cloud clusters (i.e. blobs of connected cloud pixels) with a difference value above the mean difference value of $T_{9.7}-T_{10.8}$ in the corresponding $10^{\circ} \times 10^{\circ}$ latitude/longitude region are incorporated in this average. This average then represents the $\Delta T_{\text {corr }}^{\mathrm{O}_{3}}$ for the corresponding cloud patch. In order to guarantee temporally stable results and to reduce false corrections, too small cloud objects (with less than 450 pixels, which corresponds to approx. $5000 \mathrm{~km}^{2}$ on SEVIRI over Europe) are excluded. In addition, overshooting $\mathrm{Cb}$ tops are detected and filtered out using $T_{6.2}-T_{10.8}>0 \mathrm{~K}$ (Tjemkes et al., 1997). Overshooting $\mathrm{Cb}$ tops are not suitable for this technique due to their vertical extent into the lower stratosphere, which would partly mask the effect of ozone and cause a diurnal cycle.

Since in every satellite scene only few pixels, if any, will satisfy these conditions, the correction value that is available only at single spots is then interpolated and extrapolated to the full area of observation. This is done by anisotropic kriging to take into account the zonal character of the ozone field. If no such cold cirrus are present, an empirical value of $\Delta T_{\text {corr }}^{\mathrm{O}_{3}}=4 \mathrm{~K}$ is used. After application of this correction, the BTD first shown in Fig. 5a then looks like in Fig. 5b.

Finally, viewing angle dependency was analysed in analogy to Sect. 4.2 to obtain the final revised version of Test $6 \mathrm{a}$ as in Table 2.

In the following, the original version of MeCiDA from Krebs et al. (2007) will be called MeCiDA1 while the new version described here will be referred to as MeCiDA2.

\section{Evaluation}

Our methodology to evaluate the changes introduced in the original MeCiDA algorithm (MeCiDA1) is twofold. On one side, the MODIS product CPO (see Sect. 3.2) is used as independent source of information. It is based on different physical principles than MeCiDA (it relies on solar channels, etc.) and uses data from a sensor aboard a polar orbiting satellite that, thus, sees the earth under different viewing conditions. Thus, comparison of MeCiDA1 and MeCiDA2 cirrus masks with $\mathrm{CPO}$ will give insight into the performance of the old and new MeCiDA version. On the other side, to get a more detailed information about the effect produced by the consideration of the satellite viewing dependency we decided to adapt MeCiDA to MODIS. This way, the same algorithm could be applied to cloud fields that were observed under different angles by the two sensors, the geostationary SEVIRI and the polar orbiting MODIS.

For the comparison we selected a winter and a summer month: January and July 2008, for the region between -10 and $+20^{\circ} \mathrm{E}$ (Fig. 6). This way, the latitude dependency of cirrus detection (and hence the viewing angle dependency) can be assessed. Furthermore, the selected region both contains land and ocean pixels and reaches to very high southern 

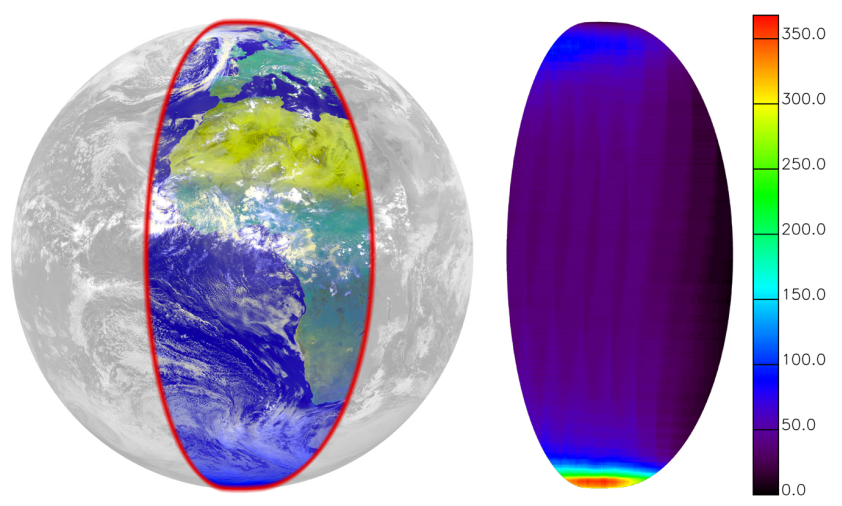

Table 3. SEVIRI (i.e. from Krebs et al., 2007) and MODIS threshold value for the MeCiDA1 tests including the BTD $T_{6.2}-T_{7.3}$.

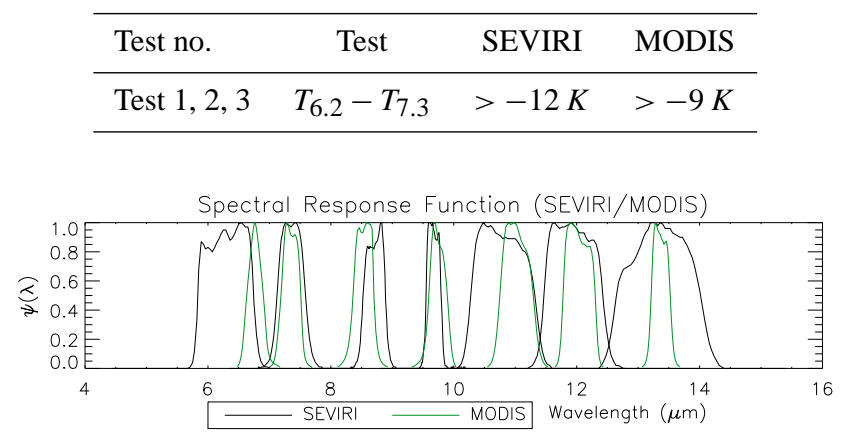

Fig. 6. Selected region for comparison between cirrus products (left panel). Numbers of synchronous observations from SEVIRI and MODIS in January 2008 (right panel).

latitudes where the ozone problem mentioned in Sect. 4.1 was encountered. For the comparisons between MeCiDA and the MODIS product CPO, we retrieved from the MODIS archive all Collection 5 MOD06 granules that intersect this region and time intervals. Since the $\mathrm{CPO}$ product makes use of solar channels, only day granules could be considered. In contrast, for the comparisons between MeCiDA on SEVIRI and MeCiDA on MODIS, all MOD02 granules could be utilized because only thermal channels were needed. In total, 1412 MODIS granules in January and 1416 MODIS granules in July were used for this comparison (MOD02 and MOD06 for each granule).

\subsection{Adaption of MeCiDA to MODIS: MoCiDA}

Since MODIS with its 36 spectral bands also covers the 11 SEVIRI channels it is possible in principle to apply MeCiDA to MODIS data. However, a closer look at the MODIS and SEVIRI spectral response functions reveals that MODIS bands are in general narrower and that the first SEVIRI water vapour channel is shifted with respect to MODIS: the SEVIRI channel is centred at $6.25 \mu \mathrm{m}$ while the corresponding MODIS channel is centred at $6.75 \mu \mathrm{m}$ (see Fig. 7).

This requires special care and a modification of the thresholds in those tests using this channel. In order to determine the needed modifications of the threshold values, we have performed radiative transfer calculations for both sensors and selected atmospheric conditions. Identical to SEVIRI (see the description of the radiative transfer calculations in Sect. 4.2), MODIS bands are simulated using LOWTRAN 7 with 15 sample points for each band. It was found that $T_{9.7, \text { SEVIRI }}-T_{9.7, \text { MODIS }}$ is always negative. This is particularly true for clear sky conditions and large satellite viewing angles, while in the presence of cirrus clouds this difference becomes less negative. The $\mathrm{CO}_{2}$ channel shows the opposite behaviour: $T_{13.4, \mathrm{SEVIRI}}-T_{13.4, \mathrm{MODIS}}$ is always positive without clouds, but it tends to zero for cirrus covered pixels. Furthermore, SEVIRI channel $5(6.25 \mu \mathrm{m})$ temperatures

Fig. 7. Spectral response functions $\psi$ of the thermal channels of SEVIRI and MODIS as a function of wavelength $\lambda$.

are colder than MODIS band 27 temperatures $(6.75 \mu \mathrm{m})$ by approximately $3 \mathrm{~K}$ in the presence of cirrus clouds such that $T_{6.2}-T_{7.3}>-12 \mathrm{~K}$ in Test 1,2 and 3 are modified to $T_{6.2}-T_{7.3}>-9 \mathrm{~K}$ (see also Table 3 ).

Dependencies of BT and BTDs on satellite viewing angles were inherited from MeCiDA2. Finally, this leaves us with two versions of MeCiDA for MODIS, called MoCiDA (MODIS Cirrus Detection Algorithm): MoCiDA1 refers to the first version of MeCiDA, as displayed in Krebs et al. (2007), while MoCiDA2 refers to the version presented in this paper including satellite viewing angle dependency and ozone correction.

Finally, we discuss here an example of comparison between MoCiDA2 and CPO by looking at Fig. 1b. Here, the difference between these two cloud masks is plotted (the MeCiDA2 mask is found in the left panel in Fig. 1 and a RGB false colour composite in Fig. 2). Two main effects appear here: (1) Around those cirrus structures that are detected by both algorithms MoCiDA2 tends to detect some additional cloud pixels. According to the violet colours of many of these additional pixels in the RGB image, this seems to suggest a higher sensitivity of MoCiDA2 with respect to CPO. (2) There is an additional cloud structure that is identified by CPO as cirrus while MoCiDA does not see it at all. Here, it seems that CPO is (correctly) detecting the iced tops of these cloud structures. Remember that the differences observed here are due only to algorithmic differences since the sensor utilised is the same for MoCiDA2 and CPO.

\subsection{Collocation of SEVIRI and MODIS and averaging}

The different viewing geometries of the SEVIRI and MODIS instruments can produce apparent spatial shifts of cloud structures, especially cirrus clouds, due to their location in the upper troposphere between approx. 8 and $12 \mathrm{~km}$ in midlatitudes or even higher in the tropics. This leads to spurious results when cirrus masks extracted from different spaceborne sensors are compared to each other. For this reason, 
we displace the cirrus clouds in such a way as to minimise these parallax effects. To reach this goal, we use the cloud top pressure (Menzel et al., 2008) contained in the MOD06 product $(5 \mathrm{~km} \times 5 \mathrm{~km})$ in combination with ECMWF ERA40 (European centre for medium-range weather forecasts, $40 \mathrm{yr}$ re-analysis project) reanalysis (Uppala et al., 2005) pressure fields to determine the geometric top height of the detected cirrus clouds. In order to suppress possible MOD06 product deficiencies and to produce meaningful values for MoCiDA pixels at the mostly semi-transparent edges of cirrus clouds, we took the maximum height in an area of $9 \times 9$ pixels centred around the pixel under consideration. When no pressure value could be found in the MOD06 product, a cirrus cloud top height of $10 \mathrm{~km}$ was assumed for this pixel.

After parallax correction, MODIS cirrus masks were projected onto the SEVIRI grid: MODIS pixels belonging to one SEVIRI pixel were averaged thus providing cirrus cloud cover for every SEVIRI grid point. As a result, a mask of cirrus clouds derived from MODIS data is obtained for the SEVIRI grid.

For the comparison between MODIS and SEVIRI, we start with a MODIS granule and select the SEVIRI slot that lies closest to the given MODIS overpass. Thus, at most an acquisition time difference of $7.5 \mathrm{~min}$ is achieved. Nevertheless, this can lead to different cloud masks because during this time clouds might have evolved. Once the MoCiDA and MeCiDA cirrus masks are obtained, the information about cirrus coverage is stored for every SEVIRI pixel contained in the region of interest (see Fig. 6). This procedure was repeated for all MODIS granules in January and July 2008. Eventually the mean frequency of cirrus occurrence is computed for every SEVIRI pixel by taking the ratio of the number of cirrus observations and the number of overall observations (temporal averaging). Finally, the region of interest is split into $5^{\circ}$ latitude boxes and the mean frequency of cirrus occurrence for a pixel inside these boxes is generated as the spatial average inside the box of all (temporal) mean pixel frequencies of cirrus occurrence.

\section{Results}

For a first illustration of the performance of MeCiDA1 and MoCiDA1 we start the following subsections with a short discussion of the sample scene displayed in Fig. 2. Then, to evaluate the effect of the changes described in Sects. 4.2 and 4.3, we discuss zonal means of cirrus cloud cover as derived from MeCiDA1 or MeCiDA2 against MoCiDA1 or MoCiDA2 or CPO as a function of latitude $\left({ }^{\circ} \mathrm{N}\right)$. Since the amount of MODIS observations is very high close to the upper and lower SEVIRI disc and because at the same time the spatial resolution of SEVIRI is very poor, we perform the comparisons between -70 and $+70^{\circ} \mathrm{N}$.

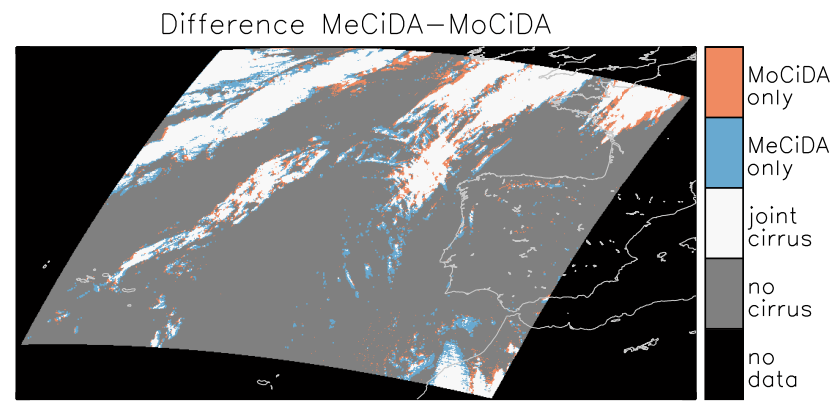

Fig. 8. Sample cirrus products for 11 January 2009, 12:00 UTC, west of Spain/Portugal. Difference between the MeCiDA2 and MoCiDA2 cirrus masks: red and blue identify cirrus pixels that are detected by MeCiDA2 or MoCiDA2 alone, white means cirrus pixels that are detected by both algorithms, while grey corresponds to cirrus free pixels.

\subsection{MeCiDA vs. MoCiDA: comparison}

In Fig. 8 the difference in cloud cover between MeCiDA2 and MoCiDA2 are plotted for the scene shown in Fig. 2. Generally speaking, both algorithms detect the same cirrus structures. Nevertheless, differences are also present and are mainly located close to cloud edges. This might be partly due to the slight acquisition time difference between the SEVIRI and the MODIS observation, during which clouds have evolved or moved. Also, the discrepancies come from the higher spatial resolution of the MODIS instrument that enables a more detailed definition of cloud contours. Finally, the different viewing geometry of the two sensors could be responsible for the disagreement. In fact, small cloud holes might disappear in the SEVIRI mask due to the slant viewing geometry of SEVIRI in this region west of Spain: this could be the case in the upper left corner of the observed granule. Furthermore, the slant optical thickness of a cirrus cloud is of course larger than the nadir optical thickness. This could result in a higher detection efficiency of SEVIRI with respect to the MODIS measurements: this could be the case for the small cirrus clouds detected by MeCiDA2 right west of the southern coast of Portugal that are not retrieved by MoCiDA2 (or only partially).

All zonal means of cirrus cover for MeCiDA1, MeCiDA2, MoCiDA1 and MoCiDA2 are shown in Fig. 9 for January (panel a) and July (panel b). In both months all curves clearly indicate the location of the Intertropical Convergence Zone (ITCZ) around the Equator where the high insolation leads to pronounced convection and to the formation of cirrus clouds. While the subtropical zones are almost cirrus free due to the general subsidence, cirrus coverage increases for latitudes higher than $\pm 30^{\circ} \mathrm{N}$.

We first discuss MeCiDA1 and MoCiDA1, the dashed black and dashed blue curve in Fig. 9a and b. The two curves in Fig. 9a run parallel, apart from latitudes south of $55^{\circ} \mathrm{S}$, where they approach each other. MeCiDA1 shows a 

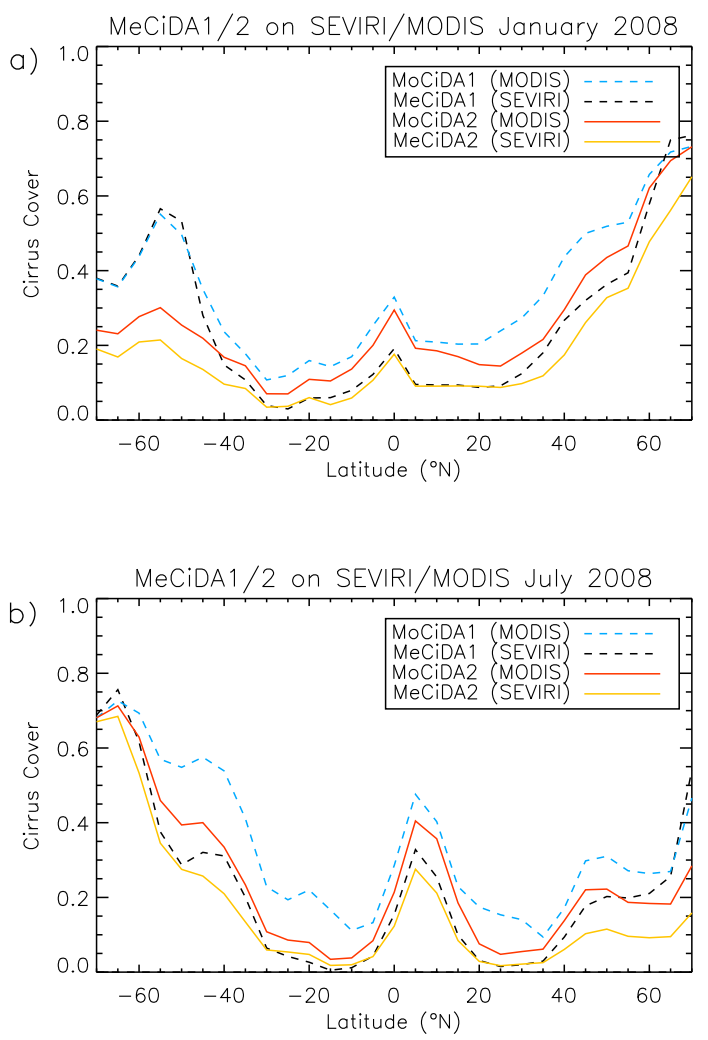

Fig. 9. Mean cirrus cloud cover during January 2008 (a) and July 2008 (b) over the selected region derived from SEVIRI (black/yellow) and MODIS (turquoise/red) using MeCiDA and MoCiDA, before (dashed lines) and after (solid lines) the enhancements.

systematically lower cirrus cover of up to 0.15 . The rapid increase towards the poles starting at $-40^{\circ} \mathrm{N}$ is very striking and is related to the uncorrected MeCiDA1 ozone dependency. Such a behaviour is not observed elsewhere and can therefore not be solely explained with the viewing angle differences between SEVIRI and MODIS. As far as MeCiDA2 and MoCiDA2 are concerned (the solid yellow and red lines in Fig. 9), we see that MoCiDA2 is still more sensitive to cirrus clouds than MeCiDA2, probably because of MODIS' higher spatial resolution. However, the difference between the yellow and red line is now smaller than between the two dashed curves (MeCiDA1 and MoCiDA1). Furthermore, the MeCiDA2 and MoCiDA2 cirrus covers differ by an approximately constant amount over the entire latitude range. This confirms the expectation that the two algorithms now work similarly well at the global scale, although the underlying sensor characteristics and satellite platform orbits differ.

Comparing MeCiDA1 with MeCiDA2, they almost coincide for latitudes between $\pm 30^{\circ}$, while MoCiDA's changes are more pronounced already in this latitude band and are largest between +20 and $+50^{\circ} \mathrm{N}$. Closer to the poles, differences between the two algorithm versions are larger.
Although a peak at around $-55^{\circ} \mathrm{N}$ is present in both versions, in version 2 of the cirrus detection schemes it is shallower.

Figure $9 \mathrm{~b}$ depicts a similar behaviour. In particular, the exceedingly high values close to $+60^{\circ} \mathrm{N}$ disappear and the overall difference between MeCiDA and MoCiDA is considerably smaller for version 2 than for version 1 . As for January, the winter hemisphere mid- to high-latitudes show high values of cirrus coverage, probably related to the enhanced occurrence of fronts with iced tops.

The values of ice cloud cover obtained with the revised versions of these algorithms (MeCiDA2, MoCiDA2) are plausible. For instance, Hagihara et al. (2010, Fig. 13c) show zonal means of cirrus coverage for September 2006November 2006 extracted from the CALIOP/CALIPSO lidar sensor (Winker et al., 2010) and the MODIS radiometer measurements. This plot can be compared to Fig. 9 in this study. The location of maxima and minima is very similar in the latitude range $\left(-30,+70^{\circ} \mathrm{N}\right)$ but MeCiDA2 and MoCiDA2 underestimate cirrus cloud coverage with respect to CALIOP by approx. 0.2 due to the higher sensitivity of the lidar instrument. Closer to the South Pole the situation is different. The strong cirrus coverage increase observed for both our MeCiDA2 and MoCiDA2 in the Southern Hemisphere does not find a counterpart in the CALIOP data where cirrus coverage only reaches $0.4-0.5$ at $-70^{\circ} \mathrm{N}$. This is consistent with Kahn et al. (2008, Fig. 5b), where zonal averages between $\pm 70^{\circ} \mathrm{N}$ of effective cloud amount or upper layer clouds and a period of five months from July to November 2006 derived from the atmospheric infrared sounder (AIRS) aboard Aqua (Aumann et al., 2003) is shown. The peak of effective cloud amount in the ITCZ at $10^{\circ} \mathrm{N}$ amounts to approx. 0.35 , then it decreases to 0.15 at $-10^{\circ} \mathrm{N}$ and 0.2 at $25^{\circ} \mathrm{N}$, and increases again to values around 0.30 at -40 and $55^{\circ} \mathrm{N}$. In the Northern Hemisphere, effective cloud amount then stays almost constant, while in the Southern Hemisphere effective cloud amount decreases to 0.15 at $-70^{\circ} \mathrm{N}$, which contrasts our observations. However, it must be noticed that effective cloud amount is the product of cloud emissivity and cloud fraction. Since emissivity for cirrus clouds is often smaller than 1, AIRS effective cloud amount and our cloud cover are not directly comparable. In a further study by Stubenrauch et al. (2010a) where climatological zonal means of high cloud cover from various sources (AIRS: 2003-2008, Path-B TOVS: 1987-1995, CALIOP: 2007-2008, ISCCP: 1984-2004) are presented for January and July (Stubenrauch et al., 2010b, Fig. 7), we do not only observe that cloud cover in our study shows a realistic behaviour, but also that the cirrus cover increase toward the South Pole in July 2008 plotted in Fig. 9 could be realistic since the CALIOP/CALIPSO has the same behaviour. In the global map of average cirrus coverage from ISCCP for 1984-1999 (Stordal et al., 2005, Fig. 1) high values above land are also shown in the Northern Hemisphere in the latitude belt between 25 and $70^{\circ} \mathrm{N}$. Thus, after all these considerations, it is not clear whether 


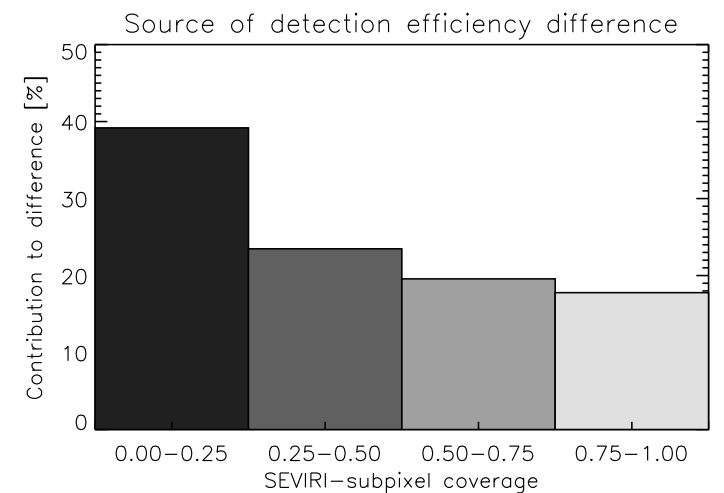

Fig. 10. Contribution of subpixel effects to the observed differences between MeCiDA2 and MoCiDA2.

the cirrus cover increase towards the poles observed with MeCiDA and MoCiDA in this study is an algorithmic artifact or a real issue. Apart from this latitude region, the cirrus coverage obtained by MeCiDA2/MoCiDA2 is consistent with recent publications.

\subsection{MeCiDA vs. MoCiDA: sub-pixel effects}

In this section we study the impact of resolution on the detection efficiency. Since MoCiDA is first applied to high resolution data (MODIS) and the resulting $1 \times 1 \mathrm{~km}^{2}$ cirrus mask is then projected to the SEVIRI grid, we can investigate the dependency of cirrus detection using SEVIRI data as a function of sub-scale cirrus coverage that can be extracted from MODIS. Generally speaking, we expect MeCiDA's performance to increase with increasing sub-pixel cirrus cover. The result of this investigation is shown in Fig. 10. Here, we collected all the data from January and July 2008 to classify those SEVIRI pixels that were identified by MoCiDA2 as cirrus covered but at the same time as cirrus free by MeCiDA2. We built four classes according to SEVIRI sub-pixel cirrus coverage: $0.00-0.25,0.25-0.50,0.50-0.75$ and $0.75-1.00$.

The most populated class is of course the first one with sub-pixel cirrus cover between 0.00 and 0.25 : in fact, $40 \%$ of all undetected pixels are covered at most to one quarter by cirrus clouds. The percentage in Fig. 10 decreases then as a function of increasing cirrus coverage, as expected. However, it is surprising that the last three categories are very similar to each other and explain more or less $20 \%$ each of the detection efficiency difference. This statistic further agrees with the observation described in Sect. 6.1, where MoCiDA2 detects a more or less constant higher amount of cirrus clouds over all latitude bins.

\subsection{MeCiDA vs. CPO}

As a comparison between MoCiDA and CPO has already been performed in Sect. 3.2 discussing Fig. 1, no additional sample scene with the differences between MeCiDA and
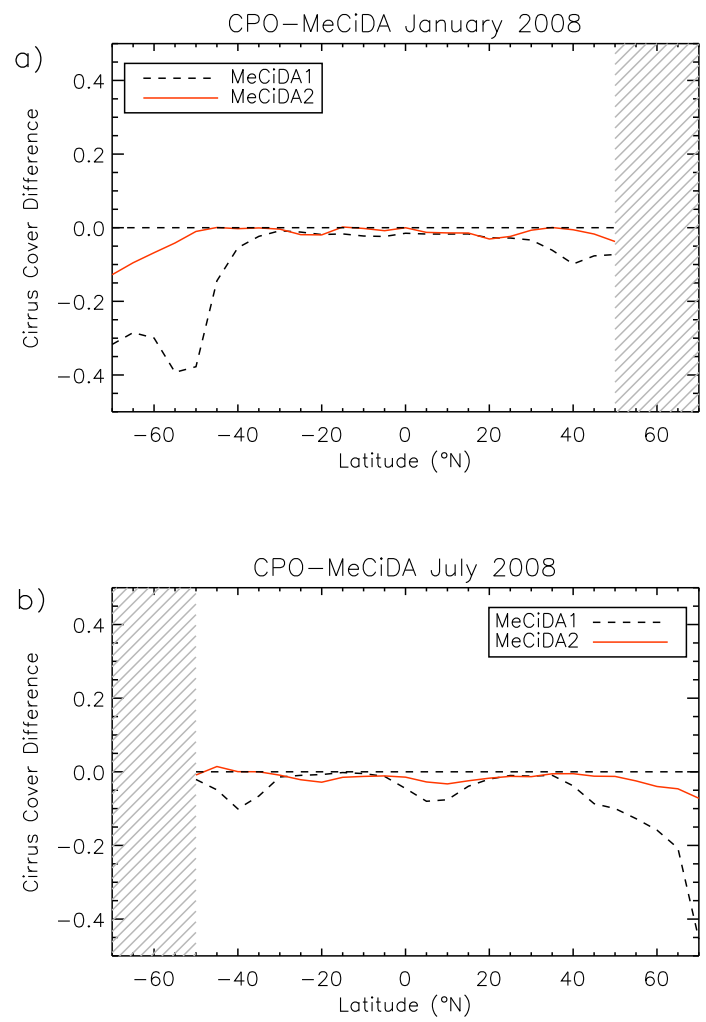

Fig. 11. Difference in mean cirrus cloud cover during January 2008 (a) and July 2008 (b) over the selected region between MeCiDA on SEVIRI and CPO on MODIS before (dashed line) and after (solid line) the enhancements. This comparison was only carried out for daylight granules, due to the usage of solar channels by the CPO product (hatched area excluded).

CPO will be shown here. In fact, MeCiDA and MoCiDA perform very similarly for this granule (see Fig. 8). Thus, we simply refer to Sect. 5.1 for a discussion of Fig. $1 \mathrm{~b}$ and to Sect. 6.1 for a discussion of Fig. 8. These considerations are still valid here.

As far as the zonal means are concerned, the anomalies observed at latitudes around $-55^{\circ} \mathrm{N}$ in January 2008 and $+60^{\circ} \mathrm{N}$ in July 2008 are evident in the comparison plots of $\mathrm{CPO}$ versus MeCiDA (Fig. 11). Here, the CPO product shows much smaller cirrus coverage than MeCiDA1 (black dashed curve). In January (Fig. 11a), differences between $-30^{\circ} \mathrm{N}$ and $+30^{\circ} \mathrm{N}$ are very low and never exceed 0.05 . Somewhat larger differences are observed at higher latitudes $\left(>40^{\circ} \mathrm{N}\right)$ where differences are of the order of 0.15 . MeCiDA2 (red solid curve) is very similar to CPO and differs from it by at most 0.15 at $-70^{\circ} \mathrm{N}$ or 0.1 at $+50^{\circ} \mathrm{N}$. In particular, the peak at $-55^{\circ} \mathrm{N}$ has disappeared. In July 2008 (Fig. 11b) the agreement between MeCiDA2 and CPO is even better. While MeCiDA1 showed large disagreement starting at $45^{\circ} \mathrm{N}$ polewards, MeCiDA2 never differs from CPO by more than 0.05 except at $60^{\circ} \mathrm{N}$ where the discrepancy amounts to 0.15 . Please notice that this agreement 
nevertheless does not imply that both algorithms MeCiDA2 and $\mathrm{CPO}$ are detecting exactly the same cirrus clouds. In fact, under some circumstances the higher cirrus detection capabilities of CPO due to the higher spatial resolution of MODIS and to the use of solar channels might be balanced by some MeCiDA2 false alarms.

\section{Conclusions}

Due to their special role for climate, it is important to monitor cirrus coverage at the global level. We presented the improved version of the day and night cirrus detection algorithm MeCiDA (Krebs et al., 2007) that uses seven thermal channels of the SEVIRI instrument aboard Met- 8 and Met9. The new algorithm, called MeCiDA2 in contrast to the original version MeCiDA1, can now be applied to the entire MSG/SEVIRI disc and takes into account the viewing angle dependency of the cirrus cloud detection and correctly deals with brightness temperatures in the ozone channel centred at $9.7 \mu \mathrm{m}$.

To evaluate the new algorithm and the impact of the proposed modifications we adapted MeCiDA to Terra/MODIS to exploit the different viewing geometry of this instrument. Furthermore, we compared to the MOD06 cloud phase optical properties (CPO) product in order to have an independent check of the algorithm performance. In both cases, the database consists of data from January and July 2008 to consider seasonal variation. The comparison was performed on a part of the SEVIRI disc between -10 and $+20^{\circ} \mathrm{E}$ to investigate viewing angle dependence.

We conclude that the consideration of viewing angle dependency and ozone effect strongly reduces false alarm rates, mainly at higher latitudes beyond $\pm 50^{\circ}$. Closer to the Equator the performance of MeCiDA has only been slightly affected by the changes. Usually, MeCiDA now detects less cirrus clouds than before. The comparison to $\mathrm{CPO}$ reveals that cirrus cloud cover difference between CPO and MeCiDA2 is smaller than 0.1 apart from latitudes higher than $50^{\circ} \mathrm{N}$. MeCiDA2 however only uses thermal information, and is thus a day and night algorithm that can be applied to produce diurnal cycles of cirrus cover.

Acknowledgements. This manuscript is dedicated to the memory of our colleague Hermann Mannstein who died unexpectedly and much too early on 25 January 2013. He was the scientific pioneer in the field of cloud remote sensing at DLR during nearly three decades. Most of his recent work was related to the detection of ice clouds in satellite data and the interaction of man-made and natural ice clouds. He will be deeply missed as expert, adviser and friend.

We thank NASA for the provision of MODIS data through http://ladsweb.nascom.nasa.gov, EUMETSAT for the provision of SEVIRI data and ECMWF for the reanalysis dataset ERA40. We would also like to extend out exceptional gratitude to Kasper Graf for providing a continuous SEVIRI dataset over the examined regions and Simon Unterstrasser and Richard Keane for the careful review.

The service charges for this open access publication have been covered by a Research Centre of the Helmholtz Association.

Edited by: A. Kokhanovsky

\section{References}

Ackerman, S., Strabala, K., Menzel, W., Frey, R., Moeller, C., and Gumley, L.: Discriminating clear sky from clouds with MODIS, J. Geophys. Res., 103, 32141-32157, 1998.

Appleman, H.: The formation of exhaust contrails by jet aircraft, B. Am. Meteorol. Soc., 34, 14-20, 1953.

Atlas, D., Wang, Z., and Duda, D.: Contrails to cirrus - morphology, microphysics, and radiative properties, J. Appl. Meteorol. Clim., 45, 5-19, 2006.

Aumann, H. H., Chahine, M., Gautier, C., Goldberg, M., Kalnay, E., McMillan, L., Revercomb, H., Rosenkranz, P., Smith, W., Staelin, D., Strow, L., and Susskind, J.: AIRS/AMSU/HSB on the Aqua mission: design, science objectives, data products, and processing systems, IEEE T. Geosci. Remote, 41, 253-264, 2003.

Baum, B., Soulen, P., Strabala, K., King, M., Ackerman, S., Menzel, W., and Yang, P.: Remote sensing of cloud properties using MODIS airborne simulator imagery during SUCCESS. 2. Cloud thermodynamic phase, J. Geophys. Res., 105, 11781-11792, 2000.

Duda, D., Minnis, P., Nguyen, L., and Palikonda, R.: A case study of the development of contrail clusters over the Great Lakes, J. Atmos. Sci., 61, 1132-1146, 2004.

Evans, K. F., Walter, S. J., Heymsfield, A. J., and Deeter, M.: Modeling of submillimeter passive remote sensing of cirrus clouds, J. Appl. Meteorol., 37, 184-205, 1998.

Hagihara, Y., Okamoto, H., and Yoshida, R.: Development of a combined CloudSat-CALIPSO cloud mask to show global cloud distribution, J. Geophys. Res., 115, D00H33, doi:10.1029/2009JD012344, 2010.

Hong, G., Heygster, G., and Kunzi, K.: Intercomparison of deep convective cloud fractions from passive infrared and microwave radiance measurements, Geosci. Remote Sens. Lett., 2, 18-22, 2005.

Jensen, E., Ackerman, A., Stevens, D., Toon, O., and Minnis, P.: Spreading and growth of contrails in a sheared environment, J. Geophys. Res., 103, 31557-31568, 1998.

Jiang, X., Pawson, S., and Camp, C.: Interannual variability and trends of extratropical ozone, Part I: Northern Hemisphere, J. Atmos. Sci., 65, 3013-3029, 2008a.

Jiang, X., Pawson, S., and Camp, C.: Interannual variability and trends of extratropical ozone, Part II: Southern Hemisphere, J. Atmos. Sci., 65, 3030-3041, 2008b.

Kahn, B. H., Chahine, M. T., Stephens, G. L., Mace, G. G., Marchand, R. T., Wang, Z., Barnet, C. D., Eldering, A., Holz, R. E., Kuehn, R. E., and Vane, D. G.: Cloud type comparisons of AIRS, CloudSat, and CALIPSO cloud height and amount, Atmos. Chem. Phys., 8, 1231-1248, doi:10.5194/acp-8-1231-2008, 2008. 
Krebs, W., Mannstein, H., Bugliaro, L., and Mayer, B.: Technical note: A new day- and night-time Meteosat Second Generation Cirrus Detection Algorithm MeCiDA, Atmos. Chem. Phys., 7, 6145-6159, doi:10.5194/acp-7-6145-2007, 2007.

Kurzeja, R.: Spatial variability of total ozone at high latitudes in winter, J. Atmos. Sci., 41, 695-697, 1984.

Lavanant, L., Fourrié, N., Gambacorta, A., Grieco, G., Heilliette, S., and Hilton, F. I., Kim, M. J., McNally, A. P., Nishihata, H., Pavelin, E. G., and Rabier, F.: Comparison of cloud products within IASI footprints for the assimilation of cloudy radiances, Q. J. Roy. Meteorol. Soc., 137, 1988-2003, doi:10.1002/qj.917, 2011.

Mayer, B. and Kylling, A.: Technical note: The libRadtran software package for radiative transfer calculations - description and examples of use, Atmos. Chem. Phys., 5, 1855-1877, doi:10.5194/acp-5-1855-2005, 2005.

Menzel, W. P., Frey, R. A., Zhang, H., Wylie, D. P., Moeller, C. C., Holz, R. E., Maddux, B., Baum, B. A., Strabala, K. I., and Gumley, L. E.: MODIS global cloud-top pressure and amount estimation: algorithm description and results, J. Appl. Meteorol. Clim., 47, 1175-1198, doi:10.1175/2007JAMC1705.1, 2008.

Minnis, P., Young, D., Garber, D., Nguyen, L., Smith Jr., W., and Palikonda, R.: Transformation of contrails into cirrus during SUCCESS, Geophys. Res. Lett., 25, 1157-1160, 1998.

Minnis, P., Ayers, J. K., Palikonda, R., and Phan, D.: Contrails, cirrus trends, and climate, J. Climate, 17, 1671-1685, 2004.

Platnick, S., King, M., Ackerman, S., Menzel, W., Baum, B., Riedi, J., and Frey, R.: The MODIS cloud products: algorithms and examples from TERRA, IEEE T. Geosci. Remote, 41, 459473, 2003.

Schlüssel, P., Hultberg, T. H., Phillips, P. L., August, T. and Calbet, X.: The operational IASI Level 2 processor, Adv. Space Res., 5, 982-988, doi:10.1016/j.asr.2005.03.008, 2005.

Schmetz, J., Pili, P., Tjemkes, S., Just, D., Kerkmann, J., Rota, S., and Ratier, A.: An introduction to Meteosat Second Generation (MSG), B. Am. Meteorol. Soc., 83, 977-992, doi:10.1175/15200477(2002)083<0977:AITMSG>2.3.CO;2, 2002.

Schmidt, E.: Die Entstehung von Eisnebel aus den Auspuffgasen von Flugmotoren, Schrift. Deut. Akad. Luftfahrtf., 44, 1-15, 1941.

Schumann, U.: On conditions for contrail formation from aircraft exhausts, Meteorol. Z., 5, 4-23, 1996.

Stordal, F., Myhre, G., Stordal, E. J. G., Rossow, W. B., Lee, D. S., Arlander, D. W., and Svendby, T.: Is there a trend in cirrus cloud cover due to aircraft traffic?, Atmos. Chem. Phys., 5, 2155-2162, doi:10.5194/acp-5-2155-2005, 2005.

Stubenrauch, C., Chédin, A., Rädel, G., Scott, N., and Serrar, S.: Cloud properties and their seasonal and diurnal variability from TOVS path-B, J. Atmos. Chem., 19, 5531-5553, 2006.
Stubenrauch, C. J., Cros, S., Guignard, A., and Lamquin, N.: A 6-year global cloud climatology from the Atmospheric InfraRed Sounder AIRS and a statistical analysis in synergy with CALIPSO and CloudSat, Atmos. Chem. Phys., 10, 7197-7214, doi:10.5194/acp-10-7197-2010, 2010a.

Stubenrauch, C. J., Cros, S., Guignard, A., and Armante, R., Chédin, A., and Scott, N.: Global Cloud Climatologies from satellite-based InfraRed Sounders (TOVS, AIRS and IASI), B. Am. Meteorol. Soc., 93, 347-370, 2010 b.

Tjemkes, S. A., van de Berg, L., and Schmetz, J.: Warm water vapour pixels over high clouds as observed by Meteosat, Beitr. Phys. Atmos., 70, 15-21, 1997.

Unterstrasser, S. and Gierens, K.: Numerical simulations of contrail-to-cirrus transition - Part 1: An extensive parametric study, Atmos. Chem. Phys., 10, 2017-2036, doi:10.5194/acp-102017-2010, 2010.

Uppala, S. M., Kållberg, P. W., Simmons, A. J., Andrae, U., Bechtold, V. D. C., Fiorino, M., Gibson, J. K., Haseler, J., Hernandez, A., Kelly, G. A., Li, X., Onogi, K., Saarinen, S., Sokka, N., Allan, R. P., Andersson, E., Arpe, K., Balmaseda, M. A., Beljaars, A. C. M., Berg, L. V. D., Bidlot, J., Bormann, N., Caires, S., Chevallier, F., Dethof, A., Dragosavac, M., Fisher, M., Fuentes, M., Hagemann, S., Hólm, E., Hoskins, B. J., Isaksen, L., Janssen, P. A. E. M., Jenne, R., McNally, A. P., Mahfouf, J.F., Morcrette, J.-J., Rayner, N. A., Saunders, R. W., Simon, P., Sterl, A., Trenberth, K. E., Untch, A., Vasiljevic, D., Viterbo, P., and Woollen, J.: The ERA-40 re-analysis, Q. J. Roy. Meteorol. Soc., 131, 2961-3012, doi:10.1256/qj.04.176, 2005.

Vaughan, M., Young, S., Winker, D., Powell, K., Omar, A., Liu, Z., $\mathrm{Hu}$, Y., and Hostetler, C.: Fully automated analysis of spacebased lidar data: an overview of the CALIPSO retrieval algorithms and data products, in: Laser Radar Techniques for Atmospheric Sensing, edited by: Singh, U. N., Vol. 5575 of Proceedings of the Society of Photo-Optical Instrumentation Engineers (SPIE), Bellingham, 16-30, doi:10.1117/12.572024, 2004.

Winker, D. M., Pelon, J., Coakley, J. A., Ackerman, S. A., Charlson, R. J., Colarco, P. R., Flamant, P., Fu, Q., Hoff, R. M., Kittaka, C., Kubar, T. L., Le Treut, H., McCormick, M. P., Mégie, G., Poole, L., Powell, K., Trepte, C., Vaughan, M. A., and Wielicki, B. A.: The CALIPSO mission: a global 3-D view of aerosols and clouds, B. Am. Meteorol. Soc., 91, 1211-1229, doi:10.1175/2010BAMS3009.1, 2010.

Wylie, D. and Wang, P.: Comparison of cloud frequency data from HIRS and SAGE II, J. Geophys. Res., 102, 29893-29900, 1997.

Wylie, D., Jackson, D., Menzel, W., and Bates, J.: Trends in global cloud cover in two decades of HIRS observations, J. Atmos. Chem., 18, 3021-3031, 2005. 